\title{
Improved affinity selection using phage display technology and off-rate based selection
}

\author{
Bin Yuan \\ Department of Chemical and Materials Engineering \\ Arizona State University \\ Tempe, AZ 85287, USA \\ Tel: 4809650826 \\ Fax: 4809650037 \\ E-mail: Bin.Yuan@asu.edu \\ Philip Schulz \\ Department of Chemical and Materials Engineering \\ Arizona State University \\ Tempe, AZ 85287, USA \\ Tel: 4809650826 \\ Fax: 4809650037 \\ E-mail: Philip.Schulz@asu.edu \\ Ruitian Liu \\ Department of Chemical and Materials Engineering \\ Arizona State University \\ Tempe, AZ 85287, USA \\ Michael R. Sierks* \\ Department of Chemical and Materials Engineering \\ Arizona State University \\ Tempe, AZ 85287, USA \\ Tel: 480-965-2828 \\ Fax: 4809650037 \\ E-mail: sierks@asu.edu
}

Financial support: This work was supported in part by grants from the NIH (AG17984), American Health Assistance Foundation (A2001-043) and the Alzheimer's Association (IIRG-01-2753).

Keywords: affinity maturation, $\beta$-amyloid $(\mathrm{A} \beta)$, dissociation rate, phage display.

Flow systems such as a BIAcore biosensor can be very efficient tools to isolate high affinity antibody fragments from affinity matured phage display libraries. Here we show that using flow based selection, we can readily isolate a variant with a 35-fold higher affinity, especially with a 7 fold better off-rate, compared to the parent clone after only a single round of selection from a second generation affinity matured phage display library. The flow system represents a fast method to isolate affinity improved antibody fragments and can be particularly useful for isolating antibodies to antigens that have poor solubility, are toxic to the host cell, or prone to aggregation.

Over $30 \%$ of the biopharmaceuticals under development in clinical trials today are recombinant antibodies (Hudson and Souriau, 2003). The powerful capabilities of surface display technology to isolate high affinity antibody fragments against a wide variety of target antigens has been frequently demonstrated (Kretzschmar and von Ruden, 2002). Antibody fragments isolated using immunotube based selection often have low affinities to the target antigen (Knappik et al. 2000) Soluble selection using magnetic beads and biotinylated antigen can lead to selection of higher affinity antibody fragments (Hawkins et al. 1992), but the soluble selection method may not be suitable for those antigens that have poor solubility or are prone to aggregation. Soluble or immunotube based selection methods also do not necessarily ensure that the selected antibody fragments will have the lowest off-rates, an important characteristic for potential clinical applications (Jirholt et al. 2001). Cell sorting methods are effective selection tools for cell surface display libraries (Yeung and Wittrup, 2002), however for antigens that are toxic, have limited solubility or are prone to aggregation, phage display technology may be preferred. An alternative

*Corresponding author 
Table 1. Characters of the selected clones from static selection and flow based selection.

\begin{tabular}{|c|c|c|c|c|c|c|c|c|c|}
\hline $\begin{array}{c}\text { Static } \\
\text { Selection }\end{array}$ & $\begin{array}{l}\text { CDR3 (L) } \\
\text { Sequence }\end{array}$ & $\begin{array}{c}\text { OD }^{1} \\
\text { Mutant/ } \\
\text { parent }\end{array}$ & $\begin{array}{c}\text { Dissoc. } \\
\text { Rate } \\
\left(\boldsymbol{k}_{\mathrm{d}}, \mathbf{s}^{-1}\right)\end{array}$ & $\begin{array}{l}\text { Affinity } \\
\text { constant } \\
\left(K_{\mathrm{D}}, \mathrm{M}\right)\end{array}$ & $\begin{array}{c}\text { Flow } \\
\text { based } \\
\text { Selection }\end{array}$ & $\begin{array}{l}\text { CDR3 (L) } \\
\text { Sequence }\end{array}$ & $\begin{array}{c}\text { OD }^{1} \\
\text { Mutant/ } \\
\text { parent }\end{array}$ & $\begin{array}{c}\text { Dissoc. } \\
\text { Rate } \\
\left(k_{\mathrm{d}}, \mathrm{s}^{-1}\right)\end{array}$ & $\begin{array}{c}\text { Affinity } \\
\text { constant } \\
\left(K_{\mathrm{D}}, \mathrm{M}\right)\end{array}$ \\
\hline $\begin{array}{c}\mathrm{H} 1 \\
\text { (parent) }\end{array}$ & NSRDSSGNHVV & 1 & $4.02 \mathrm{e}-3$ & $2.61 \mathrm{e}-6$ & $\begin{array}{c}\mathrm{H} 1 \\
\text { (parent) }\end{array}$ & NSRDSSGNHVV & 1 & $4.02 \mathrm{e}-3$ & $2.61 \mathrm{e}-6$ \\
\hline $\mathrm{A} 1$ & NSSNRPTQYVV & 1.4 & $3.79 \mathrm{e}-3$ & N.A. & A9 & NSSTPTQKHVV & 3.3 & $1.23 \mathrm{e}-3$ & N.A. \\
\hline A7 & NSSRDQEGTVV & 1.8 & $5.55 \mathrm{e}-3$ & N.A. & $\mathrm{A} 11$ & NSSPQNKTLVV & 2.5 & $2.54 \mathrm{e}-3$ & N.A. \\
\hline $\mathrm{C} 12$ & NSSKNDSVLVV & 1.6 & $1.92 \mathrm{e}-2$ & N.A. & D7 & NSSDQNITSVV & 3.6 & $8.65 \mathrm{e}-4$ & N.A. \\
\hline D5 & NSSHVILNRVV & 1.4 & $7.15 \mathrm{e}-3$ & N.A. & D9 (H1v3) & NSSTRHNPTVV & 4.1 & $6.05 e-4$ & $7.28 \mathrm{e}-8$ \\
\hline D7 & NSSDSKNRPVV & 2.0 & $6.54 \mathrm{e}-3$ & N.A. & D12 & NSSQRHLPNVV & 3.9 & $7.94 \mathrm{e}-4$ & N.A. \\
\hline $\mathrm{E} 1$ & NSSQRDSLKVV & 1.7 & $3.29 \mathrm{e}-3$ & N.A. & $\mathrm{C} 1$ & NSSIPRKLIVV & 2.4 & $1.55 \mathrm{e}-3$ & N.A. \\
\hline F11 & NSSKTSNRDVV & 1.5 & $8.25 \mathrm{e}-3$ & N.A. & $\mathrm{C} 11$ & NSSDNGSKHVV & 2.9 & $6.72 \mathrm{e}-4$ & N.A. \\
\hline $\mathrm{H} 5$ & NSSCNQDSLVV & 1.8 & $5.36 \mathrm{e}-3$ & N.A. & $\mathrm{C} 12$ & NSSHLHNHPVV & 3.2 & $3.22 \mathrm{e}-3$ & N.A. \\
\hline H9 (H1v2) & NSSYCVRTLVV & 2.2 & $7.45 e-3$ & $6.53 e-7$ & F9 & NSSKTLNVDVV & 3.6 & $1.74 \mathrm{e}-3$ & N.A. \\
\hline${ }^{2}$ Average & & & $7.40 \mathrm{e}-3$ & & & & & $1.47 \mathrm{e}-3$ & \\
\hline
\end{tabular}

$1 \mathrm{OD}$ values represent the ratio of Mutant/parent readings, where each individual reading is obtained by calculating $O D_{450-} O D_{650}$.

${ }^{2}$ Average value is the average of the nine clones isolated for each selection method.

selection method for use with phage display libraries is to use a flow system such as a biosensorwhere selection is based on dissociation rates rather than affinity constants, correlating higher affinities with longer elution times (Malmborg et al. 1996).

We constructed a second-generation phage display library by randomizing the light chain CDR3 region of a parent $\operatorname{scFv}(\mathrm{H} 1)$ isolated against $\beta$-amyloid (A $\beta)$, a peptide that aggregates readily. We then compared two different methods to select for scFv's having improved affinity to $\mathrm{A} \beta$, a static immunotube biopanning based selection, and a flow based system using a BIAcore $\mathrm{X}$ biosensor. Using the static selection method, we obtained an $\mathrm{scFv}(\mathrm{H} 1-\mathrm{v} 2)$ with a four-fold higher affinity than the parent antibody (H1), while when using the flow based system; we obtained an scFv (H1-v3) having a 35-fold higher affinity.

\section{MATERIALS AND METHODS}

A $\beta$ 1-40 was used as antigen and positive single clones were selected from the Nissim library (Nissim et al. 1994) following standard biopanning protocols (Vaughan et al. 1996). The clone, H1, which showed the highest binding activity with $A \beta$ 1-40 was isolated and used as a parent clone for affinity maturation studies.

The second generation library was constructed by randomizing the CDR3 light chain region of the parent $\mathrm{H} 1$ $\mathrm{scFv}$ using a two-step PCR protocol. The scFv gene of $\mathrm{H} 1$ was amplified first with the primers: LMB3 (5'-CAG GAA ACA GCT ATG AC-3') and CDR3-6-VL-FOR (5'-CTT GGT CCC TCC GCC GAA TAC CAC NNN NNN NNN NNN NNN NNN AGA GGA GTT ACA GTA ATA GTC AGC CTC-3') where $\mathrm{N}$ represents a random nucleotide, and then amplified again with the primers: LMB3 (5'-CAG GAA ACA GCT ATG AC-3') and JL-NOT-FOR (5'-ATT
GCT TTT CCT TTT TGC GGC CGC GCC TAG GAC GGT CAG CTT GGT CCC TCC GCC-3'). The PCR product obtained after the two PCR steps was digested with Nco I and Not I, and ligated into plasmid pHEN2 (Griffiths et al. 1994) and then transformed into E. coli TG1 cells. Biopanning using immobilized antigen on immunotubes was performed essentially as described (Vaughan et al. 1996), except that $1 \mu \mathrm{g} / \mathrm{mL} \mathrm{A} \beta$ was immobilized on the surface of the immunotubes and the second-generation library was panned for three rounds. Individual clones were randomly selected as described (Vaughan et al. 1996), and clones providing the strongest ELISA signals were selected for further characterization.

BIAcore based selection was performed as follows: $A \beta$ was diluted to $200 \mu \mathrm{g} / \mathrm{mL}$ in $10 \mathrm{mM}$ Sodium acetate buffer (pH 4.8) and immobilized onto a $\mathrm{C} 1$ chip (BIAcore) following the amine binding protocol provided by the manufacturer. $\mathrm{C} 1$ chip was used here because the short dextran linkers on the surface can facilitate access of filamentous phage particles to the immobilized antigen (Malmborg et al. 1996). Immobilization of $A \beta$ resulted in a 300 RU increase in the observed signal. For selection, $40 \mu \mathrm{L}$ of secondgeneration library stocks containing $1.3 \times 10^{13} \mathrm{cfu} / \mathrm{mL}$ were passed over the $\mathrm{C} 1$ sensor chip at a flow rate of $1 \mu \mathrm{L} / \mathrm{min}$. After association of the phage to the chip surface, unbound phage were washed off the chip using the "rinse command'. Dissociation of bound phage from the chip surface was performed using a $1 \mu \mathrm{L} / \mathrm{min}$ continuous flow of running buffer (HBS-EP, BIAcore) for 7 hrs. Regeneration of the chip surface was accomplished with $10 \mu \mathrm{L} 0.1 \mathrm{M}$ glycine$\mathrm{NaOH}, \mathrm{pH}$ 12. We collected $10 \mu \mathrm{L}$ aliquots at $3,4,5,6$, and 7 hrs during the dissociation phase and also during the regeneration step. The collected samples were immediately used to infect E. coli HB2151. Individual clones were 
(a) Static based selection

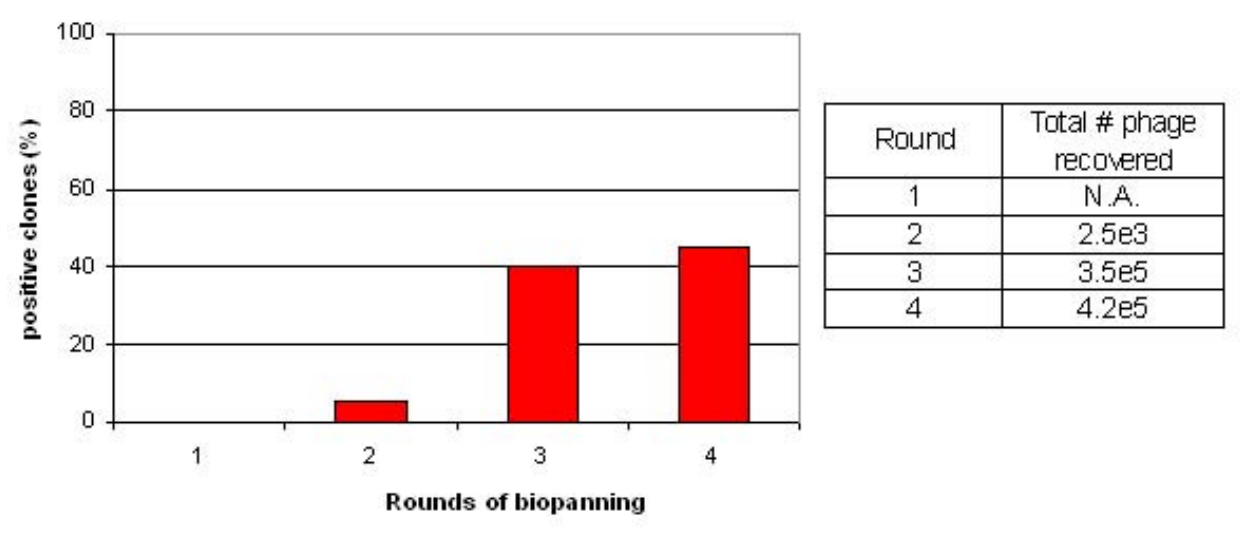

(b) Flow based selection

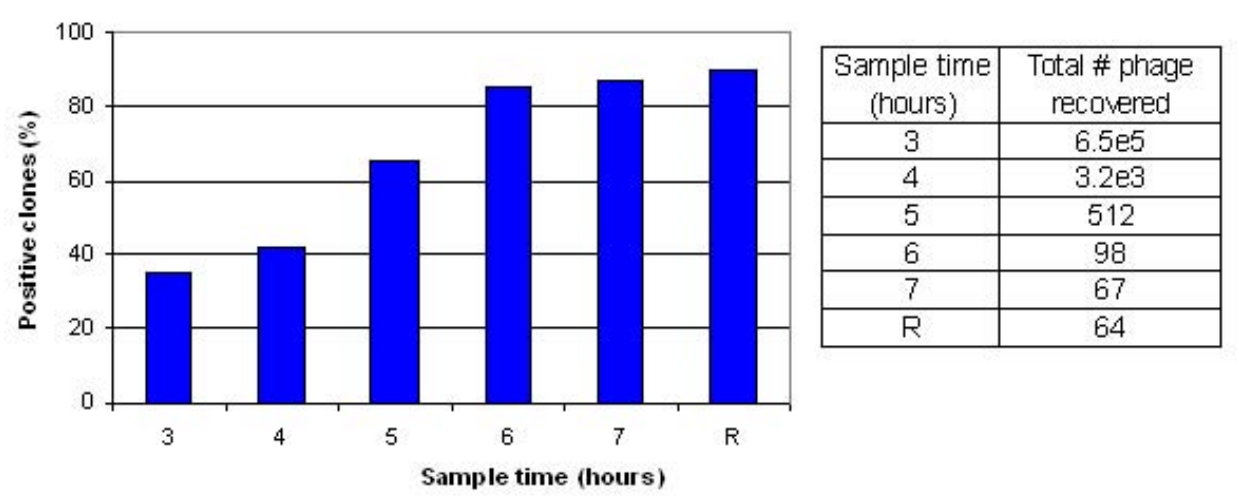

Figure 1. Percent positive clones obtained from second-generation library. Positive clones were defined as clones with an ELISA signal at least two-fold greater than the negative control.

(a) Results from four rounds of panning using immunotube based selection.

(b) Results from a single round of flow-based selection. Samples were collected after 3, 4, 5, 6 and 7 hrs and during the regeneration step $(R)$. Total phage recovered are total titers from each sample collected.

selected by ELISA as described (Vaughan et al. 1996) for further characterization.

Individual clones from immunotube and BIAcore were cultured and induced with $1 \mathrm{mM}$ IPTG. The cultures were centrifuged and filtered through a $0.2 \mu \mathrm{m}$ membrane. The resulting samples containing soluble $\mathrm{scFv}$ were used for BIAcore studies. Two clones, H1-v2, which represented the highest ELISA signal obtained from the immunotube based selection, and, H1-v3, which represented the highest ELISA signal obtained from the BIAcore based selection, were purified using a Protein A column as described and used for further characterization. The off-rates of soluble $\mathrm{scFv}$ samples obtained from crude supernatant and the on- and off-rates of purified $\mathrm{scFv}$ samples were evaluated using a BIAcore $\mathrm{X}$ biosensor. Briefly, $\mathrm{A} \beta$ was immobilized on a CM5 sensor chip by amine binding yielding a final increase of 150 RU. Samples containing scFv were serially diluted in running buffer (HBS-EP, BIAcore) and $40 \mu \mathrm{L}$ of the diluted samples were injected at a flow rate of $10 \mu \mathrm{L} / \mathrm{min}$. For the purified scFv samples (H1-v2 and H1-v3), both association rate constants $\left(k_{\mathrm{a}}\right)$ and dissociation rate constants $\left(k_{\mathrm{d}}\right)$ and the affinity constants (dissociation constants, $K_{\mathrm{D}}=k_{\mathrm{d}}\left(k_{\mathrm{a}}\right)$ were calculated assuming a single binding site model.

\section{RESULTS AND DISCUSSION}

The parent scFv, $\mathrm{H} 1\left(K_{\mathrm{D}}=2.61 \times 10^{-6} \mathrm{M}\right.$ toward $\left.\mathrm{A} \beta 1-40\right)$ was obtained after four rounds of biopanning using the Nissim phage display antibody library (Nissim et al. 1994). The second generation library has a theoretical diversity of $20^{6}\left(6.4 \times 10^{7}\right)$ and contained approximately $9.7 \times 10^{8}$ clones indicating a diversity of at least $10^{6}$ different clones. After four rounds of selection by static panning, $50 \%$ of the antibody clones recovered showed positive ELISA signals (a positive signal was defined as ELISA reading at least two times higher than the background value) (Figure 1a). 
We selected the nine different clones with the strongest ELISA signals, determined their amino acid sequences by DNA sequencing, and determined the off rates (Table 1). The clone H9 gave the highest ELISA signal, so we selected this clone for further studies, renaming it H1-v2. Flow based selection was performed on the BIAcore X. After only a single round of selection, $90 \%$ of the clones tested from the 6 and $7 \mathrm{hrs}$ and regeneration step aliquots gave positive ELISA signals (defined as above) (Figure 1b). We again selected the nine different clones with the highest ELISA signals, determined their amino acid sequence, and off rates (Table 1). The clone D9 had the highest ELISA signal, so we selected this clone for further studies, and renamed it $\mathrm{H} 1-\mathrm{v} 3$.

The average dissociation rate for the nine different clones selected using the flow-based method $\left(1.47 \times 10^{-3}\right)$ was five-fold better than the average rate for the nine clones selected by conventional immunotube panning $\left(7.40 \times 10^{-3}\right)$ (Table 1). The clone selected from flow based panning, H1$v 3$, had the lowest dissociation rate from that group, however H1v2 did not have the best dissociation rate from the static selection group.

The H1, H1-v2 and H1-v3 scFvs were purified and analyzed by BIAcore. The association rates $\left(k_{\mathrm{a}}\right)$, dissociation rates $\left(k_{\mathrm{d}}\right)$, and dissociation constants $\left(K_{\mathrm{D}}\right)$ were obtained (Table 1$)$. The dissociation constants $\left(K_{\mathrm{D}}\right)$ of H1v2 $\left(6.53 \times 10^{-7} \mathrm{M}\right)$ and H1-v3 $\left(7.28 \times 10^{-8} \mathrm{M}\right)$ are four-fold and 35 -fold better than the value obtained for the parental H1 clone $\left(2.61 \times 10^{-6} \mathrm{M}\right)$ respectively, clearly demonstrating the value of a flow-based selection method.

Another advantage of the flow based method is that the total number of recovered phage drops dramatically in those samples that contain the scFv's with the slowest off rates, facilitating identification of strong binding scFv's when limited antigen is available (Figure 1). An additional powerful feature of flow-based system is that selection can be performed very quickly, in only a few hours.

Here we demonstrate that human based $\mathrm{scFv}$ fragments that can bind $\mathrm{A} \beta$ can be isolated from a synthetic antibody library and that the affinity of these scFv's can be greatly improved (35-fold) after only a single round of affinity maturation, improving the off-rate over seven-fold. Further improvements in antibody affinity and off-rate can be obtained by generating additional antibody libraries by randomization of other CDR regions in the heavy and light chains (Yang et al. 1995), leading to antibody fragments that can be candidate therapeutics for treating Alzheimer's Disease (Lombardo et al. 2003).

\section{REFERENCES}

GRIFFITHS, A.D.; WILLIAMS, S.C.; HARTLEY, O.; TOMLINSON, I.M.; WATERHOUSE, P.; CROSBY, W.L.; KONTERMANN, R.E.; JONES, P.T.; LOW, N.M. and ALLISON, T.J. Isolation of high affinity human antibodies directly from large synthetic repertoires. The EMBO Journal, July 1994, vol. 13, no. 14, p. 3245-3260.

HAWKINS, Robert E.; RUSSELL, Stephen J. and WINTER, Greg. Selection of phage antibodies by binding affinity. Mimicking affinity maturation. Journal of Molecular Biology, August 1992, vol. 226, no. 3, p. 889896.

HUDSON, Peter J. and SOURIAU, Christelle. Engineered antibodies. Nature Medicine, January 2003, vol. 9, no. 1, p. 129-134.

JIRHOLT, Pernilla; STRANDBERG, Leif; JANSSON, Bo; KRAMBOVITIS, Elias; SODERLIND, Eskil; BORREBAECK, Carl A.K.; CARLSSON, Roland; DANIELSSON, Lena and OHLIN, Mats. A central core structure in an antibody variable domain determines antigen specificity. Protein Engineering Design and Selection, January 2001, vol. 14, no. 1, p. 67-74.

KNAPPIK, Achim; GE, Liming; HONEGGER, Annemarie; PACK, Peter; FISCHER, Melanie; WELLNHOFER, Günter; HOESS, Adolf; WOLLE, Joachim; PLUCKTHUN, Andreas and VIRNEKAS, Bernhard. Fully synthetic human combinatorial antibody libraries (HuCAL) based on modular consensus frameworks and CDRs randomized with trinucleotides. Journal of Molecular Biology, February 2000, vol. 296, no. 1, p. 57-86.

KRETZSCHMAR, Titus and VON RUDEN, Thomas. Antibody discovery: phage display. Current Opinion Biotechnology, December 2002, vol. 13, no. 6, p. 598-602.

LOMBARDO, Julianne A.; STERN, Edward A.; MCLELLAN, Megan E.; KAJDASZ, Stephen T.; HICKEY, Gregory A.; BACSKAI, Brian J. and HYMAN, Bradley T. Amyloid-beta antibody treatment leads to rapid normalization of plaque-induced neurotic alterations. The Journal of Neuroscience, November 2003, vol. 23, no. 34, p. 10879-10883.

MALMBORG, Ann-Christin; DUENAS, Marta; OHLIN, Mats; SODERLIND, Eskil and BORREBAECK, Carl A.K. Selection of binders from phage displayed antibody libraries using the BIAcore ${ }^{\mathrm{TM}}$ biosensor. Journal of Immunological Methods, October 1996, vol. 198, no. 1, p. 51-57.

NISSIM, A.; HOOGENBOOM, H.R.; TOMLINSON, I.M.; FLYNN, G.; MIDGLEY, C.; LANE, D. and WINTER, G. Antibody fragments from a 'single pot' phage display library as immunochemical reagents. The EMBO Journal, February 1994, vol. 13, no. 3, p. 692-698.

VAUGHAN, Tristan J.; WILLIAMS, Andrew J.; PRITCHARD, Kevin; OSBOURN, Jane K.; POPE, Anthony R.; EARNSHAW, John C.; MCCAFFERTY, John; HODITS, Regina A.; WILTON, Jane and 
JOHNSON, Kevin S. Human antibodies with subnanomolar affinities isolated from a large non-immunized phage display library. Nature Biotechnology, March 1996, vol. 14, no. 3, p. 309-314.

YANG, Wei-Ping; GREEN, Kimberly; PINZ-SWEENEY, Sally; BRIONES, Amelia T.; BURTON, Dennis R. and BARBAS III, Carlos F. CDR walking mutagenesis for the affinity maturation of a potent human anti-HIV-1 antibody into the picomolar range. Journal of Molecular Biology, December 1995, vol. 254, no. 3, p. 392-403.

YEUNG, Yik A. and WITTRUP, K. Dane. Quantitative screening of yeast surface-displayed polypeptide libraries by magnetic bead capture. Biotechnology Progress, MarchApril 2002, vol. 18, no. 2, p. 212-220. 